\title{
Comparison of clinical baseline characteristics between Asian and Western COPD patients in a prospective, international, multicenter study
}

This article was published in the following Dove Press journal: International Journal of Chronic Obstructive Pulmonary Disease

Kyu Yean Kim,' Marc Miravitlles, 2,3 Pawel Sliwinski, ${ }^{4}$ Richard Costello, ${ }^{5}$ Victoria Carter, ${ }^{6,7}$ Jessica Tan, $^{8}$ Therese Sophie Lapperre, ${ }^{8,9}$ Bernardino Alcazar, ${ }^{10}$ Caroline Gouder, ${ }^{1}$ Cristina Esquinas, ${ }^{2,12}$ Juan Luis García-Rivero, ${ }^{13}$ Anu Kemppinen, ${ }^{6}$ Augustine Tee, ${ }^{14}$ Miguel Roman-Rodríguez, ${ }^{15}$ Juan José Soler-Cataluña, ${ }^{3,16}$ David Price, 6,7,17 Chin Kook Rhee'

'Division of Pulmonary, Allergy and Critical Care Medicine, Department of Internal Medicine, Seoul St. Mary's Hospital, College of Medicine, The Catholic University of Korea, Seoul, Republic of Korea; ${ }^{2}$ Pneumology Department, University Hospital Vall d'Hebron/Vall d'Hebron Research Institute (VHIR), Barcelona, Spain; ${ }^{3}$ CIBER de Enfermedades Respiratorias (CIBERES), Madrid, Spain; ${ }^{4}$ 2nd Department of Respiratory Medicine, Institute of Tuberculosis and Lung Diseases, Warsaw, Poland; ${ }^{5}$ Department of Respiratory Medicine, Royal College of Surgeons, Dublin, Ireland; ${ }^{6}$ Optimum Patient Care, Cambridge, UK; ${ }^{7}$ Centre of Academic Primary Care, University of Aberdeen, Aberdeen, UK; ${ }^{8}$ Department of Respiratory Medicine, Bispebjerg Hospital, Copenhagen, Denmark; ' Singhealth Duke-NUS Medical Academic Clinical Programme, Duke-NUS Medical School, Singapore; ${ }^{10}$ Respiratory

Department, Hospital de Alta Resolución de Loja, Madrid, Spain; "'Department of Respiratory Medicine, Mater Dei Hospital, L-Imsida, Malta;

${ }^{12}$ Public Health, Mental, Maternal and Child Health Nursing Department, Faculty of Medicine and Health Sciences, University of Barcelona, Barcelona, Spain; ${ }^{13}$ Hospital Comarcal de Laredo, Cantabria, Spain; ${ }^{14}$ Department of Respiratory and Critical Care Medicine, Changi General Hospital, Singapore; ${ }^{15}$ Primary Health-care Center Son Pisà, IB-Salut, Palma, Spain; ${ }^{16}$ Pneumology Department, Hospital Arnau de Vilanova, Valencia, Spain

${ }^{17}$ Observational and Pragmatic Research Institute, Singapore

Correspondence: Chin Kook Rhe

Division of Pulmonary, Allergy and Critical Care Medicine, Department of Internal Medicine, College of Medicine, Seoul St Mary's Hospital, The Catholic University of Korea, 222 Banpo-daero, Seocho-gu, Seoul 0659I, Republic of Korea

Tel +82 222586067

Fax +82 25993589

Email chinkook77@gmail.com

\begin{abstract}
We aimed to compare clinical characteristics between Asian and Western chronic obstructive pulmonary disease (COPD) patients. This was a sub-analysis of an international, multicenter, prospective cohort study. Asian patients were enrolled in Singapore and South Korea. Western patients were enrolled in Spain, Poland, Ireland, the United Kingdom, and Malta. A total of 349 patients were analyzed. Among them, $110(32 \%)$ patients were Asian and 239 (68\%) Western. Male sex was more predominant in Asian than in Western (95\% versus 63\%, respectively; $P<0.01)$. Body mass index was significantly lower in Asian (23.5 versus $27.1 ; P<0.01)$. The proportion of patients with a history of exacerbation was lower in Asian $(12 \%$ versus $64 \% ; P<0.01)$. Although patients were enrolled by same inclusion criteria, there were several differences between Asian and Western COPD patients. Our study has shown unbiased realworld differences between Asian and Western COPD patients. Since prospective follow-up study is currently ongoing, the result of this study can be fundamental base of future analysis.
\end{abstract}

Keywords: COPD, Asian, Western

\section{Introduction}

Chronic obstructive pulmonary disease (COPD) is a heterogeneous condition requiring therapeutic management to be tailored to the clinical characteristics and disease severity of the individual patient. ${ }^{1,2}$ There is a need for regionspecific research and analysis of the epidemiology of COPD to raise awareness of the disease and highlight its causes. Such information is essential for the development of effective national health policies to ensure evidence-based deployment of finite health care resources in the prevention and management of COPD. ${ }^{3}$ The burden of COPD is rapidly growing in the Asia-Pacific region; Tan et al highlighted that there were more deaths and disability suffered from COPD in the Asian region than in developed Western countries and showed high and varied trends of hospital admissions and mortality in various Asian countries., ${ }^{4,5}$ Poverty, high rate of smoking, pulmonary tuberculosis, air pollution, and indoor biomass burning are traditionally huge issues in Asia. ${ }^{6-8}$ COPD phenotypes in Asia may be somewhat different from those in Western countries. ${ }^{9,10}$ However, there has been no definitive strategy to approach COPD patients by ethnic groups. In this study, we compared clinical characteristics between Asian and Western COPD patients to identify differences. 


\section{Methods}

This was a sub-analysis of an international, multicenter, prospective cohort study. The aim of the study was to validate the concept of clinical control in COPD. ${ }^{11}$ Eligible patients had spirometry-defined COPD (ie, postbronchodilator forced expiratory volume in 1 second $\left(\mathrm{FEV}_{1}\right)$ /forced vital capacity $\left.<0.7\right)$, were over 40 years of age, and current smokers or ex-smokers with at least 10 pack-years of tobacco exposure. The prespecified criteria of clinical control were defined by Soler-Cataluña et al. ${ }^{12,13}$ A patient was considered controlled when clinically stable and with a low impact adjusted by level of disease severity. Impact is related to the manifestations of the disease at the time of medical consultation and stability is related to the changes of the clinical status of the patient over time including the presence of exacerbations. A COPD exacerbation was defined as of any one of the following: acute use of oral corticosteroids and/or a course of antibiotics, for lower respiratory symptoms or within 5 days of an unscheduled hospital admission/emergency department attendance for acute respiratory symptoms. In this analysis, we compared clinical characteristics between Asian and Western COPD patients. Asian patients were enrolled in Singapore and South Korea. Western patients were enrolled in Spain, Poland, Ireland, the United Kingdom, and Malta. The study was approved by the local Research and Ethics Committees of each participating research site (University Hospital Vall d'Hebron, Institute of Tuberculosis and Lung Diseases, Seoul St. Mary's Hospital, Royal College of Surgeons, Singapore General Hospital, Hospital de Alta Resolución de Loja, Mater Dei Hospital, Hospital Comarcal de Laredo, Changi General Hospital, Primary Health-care Center Son Pisà, and Hospital Arnau de Vilanova) and all patients provided written informed consent. Also, this study is registered in European Network of Centres for Pharmacoepidemiology and Pharmacovigilance (EUPAS11656) and approved by Anonymised Data Ethics \& Protocol Transparency Committee (ADEPT0115).

\section{Results}

A total of 349 patients were analyzed. Among them, 110 (32\%) patients were Asian and 239 (68\%) Western. Mean age was not significantly different; however, male sex was more predominant in Asian than in Western (95\% versus
63\%, respectively; $P<0.01)$. Body mass index (BMI, $\mathrm{kg} / \mathrm{m}^{2}$ ) was significantly lower in Asian (23.5 versus $27.1 ; P<0.01)$. Fifteen percent of Asian patients belonged to the group with a BMI lower than 18.5, while only $1 \%$ of Western did. Only $5 \%$ of Asian had a BMI greater or equal to 30 , while $32 \%$ of Western did. The proportion of patients with a history of exacerbation was lower in Asian $(12 \%$ versus $64 \% ; P<0.01)$. Thus, more Asian patients were classified as Global Initiative for Chronic Obstructive Lung Disease 2017 A or B. However, there was no significant difference in $\mathrm{FEV}_{1}$, COPD assessment test (CAT), Modified Medical Research Council, chronic bronchitis phenotype, and control state (Table 1).

\section{Discussion}

Until now, published studies that directly compared Asian and Western COPD patients are scarce. Some of the information about the characteristics of Asian patients came from the analysis of patients included in randomized clinical trials with strict inclusion/exclusion criteria. ${ }^{14,15}$ Moreover, previous reports only focused on the efficacy of the drug under investigation, but not on the clinical and epidemiological differences of participants. ${ }^{15,16}$ The current study was observational, with relatively broad inclusion criteria, which provides a more realistic overview of the characteristics of patients in these countries. Of note, there were some significant differences between Asian and Western COPD patients in sex distribution, BMI, and exacerbation history, but no differences in markers of severity such as $\mathrm{FEV}_{1}$ (\% predicted), level of control, or CAT score.

A low rate of women in Asia could be explained by several reasons. First, smoking rate in women is low in Asia. According to the World Health Organization report, smoking rate in male was $25.4 \%$ and in female it was $4.8 \%$ in Singapore. In South Korea, it was $39.3 \%$ and $5.5 \%$, respectively. ${ }^{17}$ Second, there could be confounding by recruitment, as more males may seek or are referred for treatment to the tertiary centers. Third, female COPD in Asia might be underdetected.

There has been limited study that compared BMI directly between different ethnicities. In this analysis, we clearly demonstrated that the distribution of BMI 
Table I Comparison of baseline characteristics between Asian and Western COPD patients

\begin{tabular}{|c|c|c|c|c|}
\hline & Asian $(\mathrm{N}=1 \mid 0)$ & Western $(\mathbf{N}=239)$ & Total $(\mathrm{N}=349)$ & $P$-value \\
\hline Age (years), mean (SD) & $69.4(9.1)$ & $68.2(8.6)$ & $68.6(8.8)$ & 0.24 \\
\hline Sex, n (\%) & & & & $<0.01$ \\
\hline Female & $6(5)$ & $88(37)$ & $94(27)$ & \\
\hline Male & $104(95)$ & 147 (63) & $25 \mid(73)$ & \\
\hline Smoking status, n (\%) & & & & 0.59 \\
\hline Non-smoker & $0(0)$ & $3(1)$ & $3(1)$ & \\
\hline Former smoker & $83(75)$ & $172(72)$ & $255(73)$ & \\
\hline Current smoker & $27(25)$ & $64(27)$ & $91(26)$ & \\
\hline Pack-year, median (IQR) & $39(29-60)$ & $4 \mid(30-6 I)$ & $40(30-60)$ & 0.09 \\
\hline BMI $\left(\mathrm{kg} / \mathrm{m}^{2}\right)$, median (IQR) & $23.5(20.5-26.6)$ & $27.1(24 .|-3| .2)$ & $26(23-29.4)$ & $<0.01$ \\
\hline BMI category I & & & & $<0.01$ \\
\hline$\leq 21$ kg/m², n (\%) & $30(27)$ & $18(8)$ & $48(14)$ & \\
\hline$>21 \mathrm{~kg} / \mathrm{m}^{2}, \mathrm{n}(\%)$ & $80(73)$ & $221(92)$ & $30 I(86)$ & \\
\hline BMI category II & & & & $<0.01$ \\
\hline$<18.5$ kg/m², n (\%) & $17(15)$ & $3(1)$ & $20(6)$ & \\
\hline$\geq 18.5$ and $<25 \mathrm{~kg} / \mathrm{m}^{2}, \mathrm{n}(\%)$ & $55(50)$ & $75(3 I)$ & $130(37)$ & \\
\hline$\geq 25$ and $<30 \mathrm{~kg} / \mathrm{m}^{2}, \mathrm{n}(\%)$ & $32(29)$ & $85(36)$ & $117(34)$ & \\
\hline$\geq 30$ kg/m², n (\%) & $6(5)$ & $76(32)$ & $82(23)$ & \\
\hline FEV (\%), median (IQR) & $52.4(39.3-75.1)$ & $51.8(39.2-63.2)$ & $52(39.3-65.3)$ & 0.10 \\
\hline FEV $,(\%), n(\%)$ & & & & $<0.01$ \\
\hline$\leq 35 \%$ & $25(23)$ & $45(19)$ & $70(20)$ & \\
\hline $36-49 \%$ & $24(22)$ & $60(25)$ & $84(24)$ & \\
\hline $50-64 \%$ & $20(18)$ & $84(36)$ & $104(30)$ & \\
\hline$\geq 65 \%$ & $41(37)$ & $47(20)$ & $88(25)$ & \\
\hline Chronic bronchitis, n (\%) & $69(63)$ & $107(57)$ & $176(59)$ & 0.35 \\
\hline Asthma-COPD overlap, n (\%) & $9(8)$ & $28(12)$ & $37(\mathrm{II})$ & 0.31 \\
\hline Bronchiectasis, $\mathrm{n}(\%)$ & $15(14)$ & $31(13)$ & $46(13)$ & 0.85 \\
\hline Exacerbation & & & & $<0.01$ \\
\hline $0, \mathrm{n}(\%)$ & $96(88)$ & $68(36)$ & $164(55)$ & \\
\hline$\geq \mathrm{I}, \mathrm{n}(\%)$ & $13(12)$ & $119(64)$ & $132(45)$ & \\
\hline Hospital admission & & & & $<0.01$ \\
\hline $0, \mathrm{n}(\%)$ & $102(94)$ & $137(73)$ & $239(8 I)$ & \\
\hline$\geq \mathrm{I}, \mathrm{n}(\%)$ & $7(6)$ & $50(27)$ & $57(19)$ & \\
\hline mMRC, mean (SD) & I.I $(0.80)$ & $1.55(1.1)$ & $1.22(0.98)$ & 0.10 \\
\hline Grade 0 & $8(8)$ & $21(10)$ & $29(9)$ & \\
\hline Grade I & $63(64)$ & $85(39)$ & $148(47)$ & \\
\hline Grade 2 & $19(19)$ & $56(25)$ & $75(24)$ & \\
\hline Grade 3 & $8(8)$ & $41(19)$ & 49 (I5) & \\
\hline Grade 4 & $0(0)$ & $17(8)$ & $17(5)$ & \\
\hline
\end{tabular}


Table I (Continued).

\begin{tabular}{|c|c|c|c|c|}
\hline & Asian $(\mathbf{N}=\mid 10)$ & Western $(\mathbf{N}=239)$ & Total $(\mathrm{N}=349)$ & $P$-value \\
\hline CAT & & & & 0.53 \\
\hline Median (IQR) & $12(9 ; 18)$ & $13(9 ; 20)$ & $13(9 ; 19)$ & \\
\hline mean $(S D)$ & $9.1(4.2)$ & II.2(4.90) & $10.06(4.53)$ & \\
\hline Minutes walked per day, median (IQR) & $60(45 ; 120)$ & $60(30 ; 120)$ & $60(30 ; 120)$ & 0.08 \\
\hline Control, n (\%) & & & & 0.21 \\
\hline No & $90(92)$ & $207(95)$ & $297(94)$ & \\
\hline Yes & $8(8)$ & $10(5)$ & $18(6)$ & \\
\hline GOLD 20I7, n (\%) & & & & $<0.01$ \\
\hline A & $22(23)$ & $18(11)$ & $40(15)$ & \\
\hline B & $66(68)$ & $72(43)$ & $138(52)$ & \\
\hline C & $2(2)$ & $10(6)$ & $12(5)$ & \\
\hline $\mathrm{D}$ & $7(7)$ & $69(4 I)$ & $76(29)$ & \\
\hline
\end{tabular}

Abbreviations: COPD, chronic obstructive pulmonary disease; SD, standard deviation; BMI, body mass index; IQR, interquartile range; FEV ${ }_{1}$, forced expiratory volume in I second; mMRC, modified Medical Research Council; CAT, COPD assessment test.

was significantly different between Asian and Western COPD patients. BMI is an important prognostic factor in COPD since it is included in the BODE index, which is a powerful tool to predict mortality. ${ }^{18}$ The BODE index is developed in Western COPD populations. Since our data showed that BMI is lower in Asian, the role and cut-off value of BMI in Asian might be different. Further studies regarding BMI in Asian COPD populations are definitely needed.

In this study, the history of exacerbation between two groups differed significantly despite similar $\mathrm{FEV}_{1}$ and symptom severity. This could be due to differences in management of COPD between Asian and Western countries, or differences in type of hospital where patients were recruited. Further studies regarding the differences in exacerbation rate between Asian and Western are needed.

How these differences between Asian and Western patients affect clinical outcomes needs to be elucidated. Since this sub-analysis was based on a prospective cohort, we plan to analyze and compare the longitudinal outcomes between the two groups in terms of exacerbations and control status.

There are limitations in this study. First, Asian population only came from two countries and their number was much smaller. Second, it could have been better if we made comparison with populations of other ethnic groups and origins such as Americans and Africans. However, Western patients in this study were enrolled in only European countries.

\section{Conclusion}

In conclusion, predominant male gender, lower BMI, and lower exacerbation history were characteristics of Asian COPD patients when compared with Western. Our study has provided unbiased real-world differences between Asian and Western COPD patients. Since prospective follow-up study is currently ongoing, the result of this study can be fundamental base of future analysis. How these differences between Asian and Western patients affect clinical outcomes needs to be elucidated in the future.

\section{Acknowledgments}

The study was designed and coordinated by the Respiratory Effectiveness Group (REG; www.effectivenessevaluation. org; Cambridge, UK) and delivered by Optimum Patient Care (OPC; www.optimumpatientcare.org). The following investigators participated in the study: Spain: Marc Miravitlles, Cristina Esquinas, Miriam Barrecheguren, Alexa Nuñez, Hospital Universitari Vall d'Hebron, Barcelona. Bernardino Alcazar, Hospital de Alta Resolución de Loja. Juan Luis García-Rivero, Karina Hueso, Hospital Comarcal de Laredo, Cantabria. Miguel 
Roman-Rodríguez, Primary Health-care Center Son Pisà. IB-Salut. Palma de Mallorca. Poland: Pawel Sliwinsk Sliwinski, Katarzyna Iwan, Jacek Kolakowski, Institute of Tuberculosis and Lung Diseases, Warsaw. Korea: Chin Kook Rhee, Esther Ahn, St Mary's Hospital. Seoul. Singapore: Jessica Tan, Therese Lapperre, Karen Tan Li Leng, Nicole Chia, Ong Thun How, Syifa Binte Shamsuddin, Sherine Lim Shu Gim, Yap Chwee Bee, Soh Rui Ya, Singapore General Hospital. Augustine Tee, Jun Jie Yan, Samuel Hong, William Tan, Jessica Tan, Changi General Hospital. UK: Victoria Carter, Latife Hardaker, Andrew McLaughlin, Optimum Patient Care, Cambridge. Malta: Caroline Gouder, Mater Dei Hospital. Ireland: Richard W Costello, Royal College of Surgeons. Dublin. The study was funded by an unrestricted grant from Novartis AG.

\section{Disclosure}

Dr Marc Miravitlles received speaker and/or consulting and personal fees from AstraZeneca, Bial, Boehringer Ingelheim, Chiesi, Cipla, CSL Behring, Laboratorios Esteve, Ferrer, Gebro Pharma, GlaxoSmithKline, Grifols, Menarini, Mereo Biopharma, Novartis, pH Pharma, Rovi, TEVA, Verona Pharma and Zambon, and research grants from GlaxoSmithKline and Grifols outside the submitted. Professor Pawel Sliwinski received speaker fees and nonfinancial support from Boehringer Ingelheim, AstraZeneca, Chiesi, GlaxoSmithKline, Grifols, Novartis, Roche and Teva, and consulting fees from Boehringer Ingelheim, GlaxoSmithKline, Chiesi, Grifols, Novartis, and Roche, outside the submitted work. Dr CK Rhee received consulting/lecture fees from MSD, AstraZeneca, Novartis, GSK, Takeda, Mundipharma, Sandoz, Boehringer-Ingelheim, and Teva-Handok. Dr Richard Costelloe has board membership with GSK, Aerogen, Novartis, and Teva Pharmaceuticals; consultancy agreements with, Aerogen, GlaxoSmithKline, Novartis, Teva Pharmaceuticals, and Vitalograph as well as grants and unrestricted funding for investigator-initiated studies from Vitalograph, Aerogen and GlaxoSmithKline. Dr Bernardino Alcazar reports personal fees grants, and nonfinancial support from Novartis AG, BoehringerIngelheim, GSK, personal fees from AztraZeneca, grants and personal fees from Laboratorios Menarini, Laboratorios Rovi, Laboratorios Ferrer, outside the submitted work, in addition, he has a patent WO2018/ 215686A1 issued. Dr Augustine Tee received research fund from The Respiratory Effectiveness Group, during the conduct of the study; has participated as a member of the local COPD advisory board for AstraZeneca, GlaxoSmithKline, Bayer, Takeda, and Novartis, and has received meeting/conference travel grants from Boehringer Ingelheim, Novartis, AstraZeneca, and GlaxoSmithKline. Ms Victoria Carter reports funding this study by an unrestricted grant from Novartis AG, during the conduct of the study; also she is an employee of the Observational and Pragmatic Research Institute Pte Ltd (OPRI), and Optimum Patient Care. Dr Juan José SolerCataluña has received speaker fees from AstraZeneca, grants, personal fees, non-financial support from Boehringer Ingelheim, non-financial support from Chiesi, Esteve, Ferrer, GSK, Menarini, Novartis, and Pfizer, and consulting fees from AirLiquide, Boehringer Ingelheim, Chiesi, GSK, AstraZeneca, Ferrer, and Novartis outside the submitted work. Professor David Price has board membership with Aerocrine, Amgen, AstraZeneca, Boehringer Ingelheim, Chiesi, Mylan, Mundipharma, Napp, Novartis, Regeneron Pharmaceuticals, Sanofi Genzyme, Teva Pharmaceuticals; consultancy agreements with Almirall, Amgen, AstraZeneca, Boehringer Ingelheim, Chiesi, GlaxoSmithKline, Mylan, Mundipharma, Napp, Novartis, Pfizer, Teva Pharmaceuticals, Theravance; grants and unrestricted funding for investigator-initiated studies (conducted through Observational and Pragmatic Research Institute Pte Ltd) from Aerocrine, AKL Research and Development Ltd, AstraZeneca, Boehringer Ingelheim, British Lung Foundation, Chiesi, Mylan, Mundipharma, Napp, Novartis, Pfizer, Regeneron Pharmaceuticals, Respiratory Effectiveness Group, Sanofi Genzyme, Teva Pharmaceuticals, Theravance, UK National Health Service, Zentiva (Sanofi Generics); payment for lectures/ speaking engagements from Almirall, AstraZeneca, Boehringer Ingelheim, Chiesi, Cipla, GlaxoSmithKline, Kyorin, Mylan, Merck, Mundipharma, Novartis, Pfizer, Regeneron Pharmaceuticals, Sanofi Genzyme, Skyepharma, Teva Pharmaceuticals; payment for manuscript preparation from Mundipharma, Teva Pharmaceuticals; payment for the development of educational materials from Mundipharma, Novartis; payment for 
travel/accommodation/meeting expenses from Aerocrine, AstraZeneca, Boehringer Ingelheim, Mundipharma, Napp, Novartis, Teva Pharmaceuticals; funding for patient enrolment or completion of research from Chiesi, Novartis, Teva Pharmaceuticals, Zentiva (Sanofi Generics); stock/ stock options from AKL Research and Development Ltd which produces phytopharmaceuticals; owns 74\% of the social enterprise Optimum Patient Care Ltd (Australia and UK) and 74\% of Observational and Pragmatic Research Institute Pte Ltd (Singapore); and is peer reviewer for grant committees of the Efficacy and Mechanism Evaluation programme, and Health Technology Assessment. Dr Miguel Roman-Rodríguez has received speaker fees from AstraZeneca, Boehringer Ingelheim, Chiesi, Gebro Pharma, GlaxoSmithKline, Menarini, Mundipharma, Novartis, Pfizer, and Teva, and consulting/ personal fees from AstraZeneca, Boehringer Ingelheim, GlaxoSmithKline, and Novartis outside the submitted work. The authors report no other conflicts of interest in this work.

\section{References}

1. Yoo SH, Lee JH, Yoo KH, Jung K-S, Rhee CK. Different pattern of chronic obstructive pulmonary disease assessment test score between chronic bronchitis and non-chronic bronchitis patients. Tuberc Respir Dis (Seoul). 2018. doi:10.4046/trd.2017.0088

2. Spanish COPD Guidelines (GesEPOC) 2017; Miravitlles M, Soler-Catalu ña JJ, Calle M, et al. Pharmacological treatment of stable chronic obstructive pulmonary disease. Archivos De Bronconeumología. 2017;53 (6):324-335. doi:10.1016/j.arbr.2017.03.017

3. Tan WC. Trends in chronic obstructive pulmonary disease in the Asia-Pacific regions. Curr Opin Pulm Med. 2011;17(2):56-61. doi:10.1097/MCP.0b013e32834316cd

4. Tan WC, Ng TP. COPD in Asia: where east meets west. Chest. 2008;133(2):517-527. doi:10.1378/chest.07-1131

5. Tan WC, Seale P, Ip M, et al. Trends in COPD mortality and hospitalizations in countries and regions of Asia-Pacific. Respirology. 2009;14(1):90-97. doi:10.1111/j.1440-1843.2008.01415.x
6. Rhee CK, Yoo KH, Lee JH, et al. Clinical characteristics of patients with tuberculosis-destroyed lung. Int J Tuberc Lung Dis. 2013;17 (1):67-75. doi:10.5588/ijtld.12.0351

7. Gordon SB, Bruce NG, Grigg J, et al. Respiratory risks from household air pollution in low and middle income countries. Lancet Respir Med. 2014;2(10):823-860. doi:10.1016/S22132600(14)70168-7

8. Park J, Lim MN, Hong Y, Kim WJ. The influence of Asian dust, haze, mist, and fog on hospital visits for airway diseases. Tuberc Respir Dis (Seoul). 2015;78(4):326-335. doi:10.4046/ $\operatorname{trd} .2015 .78 .4 .326$

9. Loh LC. Chronic bronchitis is not necessary to define COPD. Respirol. 2011;16(3):574. doi:10.1111/j.1440-1843.2011.01931.x

10. Koblizek V, Milenkovic B, Barczyk A, et al. Phenotypes of COPD patients with a smoking history in Central and Eastern Europe: the POPE study. Eur Respir J. 2017;49:5. doi:10.1183/13993003.014462016

11. Miravitlles M, Sliwinski P, Rhee CK, et al. Evaluation of criteria for clinical control in a prospective, international, multicenter study of patients with COPD. Respir Med. 2018;136:8-14. doi:10.1016/j. rmed.2018.01.019

12. Jose Soler-Cataluna J, Alcazar-Navarrete B, Miravitlles M. The concept of control in COPD: a new proposal for optimising therapy. Eur Respir J. 2014;44(4):1072-1075. doi:10.1183/ 09031936.00064414

13. Soler-Cataluña JJ, Marzo M, Catalan P, et al. Validation of clinical control in COPD as a new tool for optimizing treatment. Int J Chron Obstruct Pulmon Dis. 2018;13:3719-3731. doi:10.2147/COPD. S178149

14. Zhong N, Moon HS, Lee KH, et al. TIOtropium Safety and Performance In Respimat((R)) (TIOSPIR(TM)): analysis of Asian cohort of COPD patients. Respirology. 2016;21(8):1397-1403. doi:10.1111/resp. 12856

15. Ichinose M, Nishimura M, Akimoto M, et al. Tiotropium/olodaterol versus tiotropium in Japanese patients with COPD: results from the DYNAGITO study. Int $J$ Chron Obstruct Pulmon Dis. 2018;13:2147-2156. doi:10.2147/COPD.S169941

16. Wedzicha JA, Zhong N, Ichinose M, et al. Indacaterol/glycopyrronium versus salmeterol/fluticasone in Asian patients with COPD at a high risk of exacerbations: results from the FLAME study. Int J Chron Obstruct Pulmon Dis. 2017;12:339-349. doi:10.2147/COPD.S125058

17. World Health Organization. WHO report on the global tobacco epidemic 2017; 2017 Available from: https://www.who.int/tobacco/glo bal_report/2017/en/.

18. Celli BR, Cote CG, Marin JM, et al. The body-mass index, airflow obstruction, dyspnea, and exercise capacity index in chronic obstructive pulmonary disease. $N$ Engl J Med. 2004;350(10):1005-1012. doi:10.1056/NEJMoa021322 


\section{Publish your work in this journal}

The International Journal of COPD is an international, peer-reviewed journal of therapeutics and pharmacology focusing on concise rapid reporting of clinical studies and reviews in COPD. Special focus is given to the pathophysiological processes underlying the disease, intervention programs, patient focused education, and self management protocols. This journal is indexed on PubMed Central, MedLine and CAS. The manuscript management system is completely online and includes a very quick and fair peer-review system, which is all easy to use. Visit http://www.dovepress.com/testimonials.php to read real quotes from published authors. 